\title{
Rapid assessment of bovine colostrum quality: How reliable are transmission infrared spectroscopy and digital and optical refractometers?
}

\author{
I. Elsohaby, ${ }^{+} \dagger^{1}$ J. T. McClure,${ }^{*}$ M. Cameron, ${ }^{*}$ L. C. Heider, ${ }^{*}$ and G. P. Keefe ${ }^{*}$ \\ *Department of Health Management, Atlantic Veterinary College, University of Prince Edward Island, Charlottetown, Prince Edward Island, \\ Canada C1A 4P3 \\ †Infectious Diseases, Department of Animal Medicine, Faculty of Veterinary Medicine, Zagazig University, Zagazig City 44511, \\ Sharkia Province, Egypt
}

\section{ABSTRACT}

The objectives of this study were to evaluate the performance of the transmission infrared (IR) spectroscopic method and digital and optical Brix refractometers for measurement of colostral IgG concentration and assessment of colostrum quality of dairy cows. Colostrum samples $(\mathrm{n}=258)$ were collected from Holstein cows on 30 commercial dairy farms in Nova Scotia and Newfoundland, Canada. Colostral IgG concentrations of 255 samples were measured by the reference radial immunodiffusion (RID) assay and IR spectroscopy. The Brix scores were determined on 240 of these samples using both the digital and optical Brix refractometers. Approximately half $(48 \%)$ of the colostrum samples had RID IgG concentrations $<50 \mathrm{~g} / \mathrm{L}$, which was the cut-point for poor quality. The correlation between RID and IR IgG concentrations was 0.88 . The correlations between RID IgG concentration and Brix scores, as determined by the digital and optical refractometers, were 0.72 and 0.71 , respectively. The optimal cutoff levels for distinguishing good- and poor-quality colostrum using IR spectroscopy, and digital and optical Brix refractometers were at $35 \mathrm{~g} / \mathrm{L}$ and $23 \%$ Brix, respectively. The IR spectroscopy showed higher sensitivity (90\%) and specificity $(86 \%)$ than the digital (74 and $80 \%$, respectively) and optical (73 and $80 \%$, respectively) Brix refractometers for assessment of colostrum quality, as compared with RID. In conclusion, the transmissionIR spectroscopy is a rapid and accurate method for assessing colostrum quality, but is a laboratory-based method, whereas Brix refractometers were less accurate but could be used on-farm.

Key words: infrared spectroscopy, Brix refractometer, immunoglobulin $\mathrm{G}$, radial immunodiffusion assay

Received August 4, 2016.

Accepted October 25, 2016.

${ }^{1}$ Corresponding author: ielsohaby@upei.ca

\section{INTRODUCTION}

Colostrum is a critical source of immunoprotection and nutrition for newborn calves (Bielmann et al., 2010). Ingestion of good-quality colostrum during the first $24 \mathrm{~h}$ of life is essential for the future health and performance of dairy calves (Rauprich et al., 2000). Insufficient ingestion or absorption of colostral $\mathrm{IgG}$ results in failure of transfer of passive immunity (Calloway et al., 2002; Godden, 2008). Calves with failure of transfer of passive immunity (serum IgG $<10 \mathrm{~g} / \mathrm{L}$ ) are more susceptible to infectious diseases and have higher morbidity and mortality rates (Robison et al., 1988; Donovan et al., 1998; Virtala et al., 1999). Thus, it is important to assess colostrum quality before feeding to calves. Only $53 \%$ of US dairy operations routinely evaluate colostrum quality as part of their replacement heifer management, and $45 \%$ of these operations depend on visual appearance to assess colostrum quality (USDA, 2016).

Several methods have been developed to evaluate colostrum quality by measuring the colostral IgG concentration either directly or indirectly, but few of them are applicable to farm or field conditions. The radial immunodiffusion (RID) assay is regarded the most accurate reference method for directly measuring bovine colostral IgG content (McBeath et al., 1971; Oyeniyi and Hunter, 1978; Fleenor and Stott, 1980). However, this assay is a laboratory-based method, requires 18 to $24 \mathrm{~h}$ to obtain results, has high cost, lacks automation, and uses reagents with a short shelf-life (Riley et al., 2007; Bielmann et al., 2010). Thus, the RID assay is not practical for timely, routine on-farm monitoring of colostrum quality.

The colostrometer and Brix refractometer are the most common indirect methods for evaluating colostrum quality on-farm. Colostrometers measure the specific gravity of colostrum and provide an estimate of relative quality, not precise IgG concentrations (Fleenor and 
Stott, 1980; Pritchett et al., 1991). Results from the colostrometer are affected by colostrum temperature and total content of all solids, not just IgG (Mechor et al., 1992; Morin et al., 2001); moreover, it is fragile and needs to be carefully cleaned before use (Bielmann et al., 2010; Bartier et al., 2015). Only 4\% of farms in Quebec and $11 \%$ of farms in the United States have been reported to use the colostrometer consistently (Vasseur et al., 2010; USDA, 2016). Brix refractometers, either digital or optical, can be used to estimate colostral IgG levels (Bielmann et al., 2010; Bartier et al., 2015; Morrill et al., 2015). Previous studies reported a strong correlation between Brix scores and $\operatorname{Ig} G$ concentrations, as determined by RID (Chigerwe et al., 2008; Bielmann et al., 2010; Bartier et al., 2015). Unlike the colostrometer, the Brix refractometer is not sensitive to ambient temperature (Bielmann et al., 2010; Bartier et al., 2015) and is less fragile. Thus, Brix refractometers have been promoted by the dairy industry as an effective on-farm tool to estimate colostral $\operatorname{IgG}$ and colostrum quality (Thornhill et al., 2015). However, only 4\% of US dairy producers routinely use Brix refractometers to evaluate colostrum quality (USDA, 2016).

Recently, infrared (IR) spectroscopy, in combination with multivariate data analysis, has emerged as an alternative technique for assessing colostrum quality (Rivero et al., 2012; Elsohaby et al., 2016b). Infrared spectroscopy has several advantages that overcome the drawbacks associated with other methods. It is a rapid, low-cost test, requires minimal sample preparation, and 1 spectrum can be used for quantitative analysis of several components (Shaw et al., 1998; Shaw and Mantsch, 1999, 2000). A small, compact, portable infrared spectroscope has been manufactured that is ideally suited for field use on the farm, veterinary clinic, or small laboratory (Santos et al., 2013). Infrared spectroscopy, in combination with partial least squares (PLS) regression, has been widely used for quantifying human serum total protein and glucose (Ward et al., 1989; Shaw et al., 1998), bovine milk protein, lipid, and lactose analysis (Rutten et al., 2011a,b), as well as serum IgG in bovines (Elsohaby et al., 2014, 2016a), equines (Riley et al., 2007), and camelids (Burns et al., 2014). To our knowledge, no study has validated the use of IR spectroscopy for quantifying colostral IgG and assessing colostrum quality in dairy cows. Thus, the objectives of our study were (1) to investigate the utility of previously built PLS models (Elsohaby et al., 2016b) for quantifying colostral IgG concentration and assessing colostrum quality in dairy cows using IR spectroscopy, and (2) to determine and compare the diagnostic test characteristics of IR spectroscopy and digital and optical Brix refractometers for assessing colostrum quality.

\section{MATERIALS AND METHODS}

\section{Colostrum Sample Collection}

Colostrum samples $(\mathrm{n}=258)$ were collected between April and September 2015 from Holstein dairy cows on 30 commercial dairy farms in Nova Scotia $(\mathrm{n}=24)$ and Newfoundland $(\mathrm{n}=6)$, Canada. Herds were selected by veterinary clinics in the study area and were asked to provide 10 colostrum samples. Colostrum was collected by farm staff between 1 and $15 \mathrm{~h}$ after calving, and each farm delivered between 4 and 12 samples. At each farm, $50 \mathrm{~mL}$ of colostrum were collected in a vial labeled with the farm name, cow identification number, and date of collection, and then stored on the farm at $-20^{\circ} \mathrm{C}$ until transportation to the Maritime Quality Milk Laboratory, University of Prince Edward Island. All samples arrived frozen and were placed at $-20^{\circ} \mathrm{C}$ for later analysis. This study was conducted in accordance with the Canadian Council on Animal Care guidelines (CCAC, 2009) under a protocol approved by the Animal Care Committee at University of Prince Edward Island.

\section{Colostrum Sample Analysis}

RID Assay. A commercial RID assay (Bovine IgG RID Kit; Triple J Farms; Bellingham, WA) was used as the reference method for measuring colostral IgG concentrations. Colostrum samples were thawed at room temperature $\left(20-24^{\circ} \mathrm{C}\right)$ and vortexed for $10 \mathrm{~s}$. Thawed samples were diluted (1:4) with deionized sterile water and mixed by vortexing at a maximum of 2,700 rpm for $10 \mathrm{~s}$. After dilution, the RID assay was performed according to manufacturer's instructions, using $5 \mu \mathrm{L}$ of diluted colostrum in each well, and tested alongside the manufacturer's standard. The RID plates were incubated at room temperature for 18 to $24 \mathrm{~h}$ and the precipitating ring diameter surrounding the well was measured using a hand-held caliper. Colostrum samples with IgG concentration greater than the manufacturer's stated performance range for the assay $(>30 \mathrm{~g} / \mathrm{L})$ were diluted (1:6) with deionized sterile water and retested. Samples that still showed IgG concentrations above the standard range were considered good-quality colostrum for diagnostic tests, but they were excluded from the correlation analysis $(\mathrm{n}=3)$. To account for plate-toplate variation, the same IgG standard (same lot) was used on all RID assays, and each of the assay standards and colostrum samples was tested in duplicate. The average of the assay standards was used to build a calibration curve to determine the IgG concentration for each colostrum sample. The final IgG concentration for each sample was determined by calculating the average 
of the 2 replicates. The results were considered acceptable if the coefficient of determination of the calibration curve derived from the standards was equal to or greater than 0.97 .

Infrared Spectroscopy. Thawed colostrum samples were diluted (1:3) with deionized sterile water and vortexed at a maximum of 2,700 rpm for $10 \mathrm{~s}$ to ensure a uniform dispersion of colostral components. Each diluted colostrum sample was tested in replicates of 6 by evenly spreading $5-\mu \mathrm{L}$ aliquots into 5 -mm diameter wells within an adhesive-masked, 96-well silicon microplate (Riley et al., 2007). An empty well served as the background reference for each microplate. The loaded microplates were allowed to dry at room temperature $\left(20-24^{\circ} \mathrm{C}\right)$ for $2 \mathrm{~h}$, resulting in dried, thin films. For collection of the spectra, the microplates were inserted into a multisampler (HTS-XT Autosampler, Bruker Optics, Milton, ON, Canada) interfaced with an IR spectrometer (Tensor 37, Bruker Optics) equipped with a deuterium tryglycine sulfate detector and controlled by proprietary software (OPUS ver. 6.5, Bruker Optics). A total of 1,548 (258 samples $\times 6$ replicates) spectra were collected over the wavenumber range between 4,000 and $400 \mathrm{~cm}^{-1}$ with a nominal resolution of $4 \mathrm{~cm}^{-1}$, with 512 scans collected for data acquisition.

Collected spectra were converted into a printable format using manufacturer's software (GRAMS/AI ver. 7.02, Thermo Fisher Scientific Inc., Waltham, MA). The printable format spectral data were imported into MATLAB (MathWorks R2016a, Natick, MA), and then preprocessed using the same techniques used previously for developing the PLS model (Elsohaby et al., 2016b). A previously developed PLS model built for prediction of colostral IgG concentration from IR spectra (Elsohaby et al., 2016b) was used to predict colostral IgG concentrations in the 258 samples. The IgG concentration was predicted from each spectrum and, subsequently, the IgG concentration for each colostrum sample was calculated as the average of the 6 replicate IgG values.

Refractometer Readings. Thawed colostrum samples were vortexed for $10 \mathrm{~s}$ and then tested using a digital Brix refractometer (PAL-1, Atago Co. Ltd., Bellevue, WA), with a scale from 0 to $52 \%$ Brix, and an optical Brix refractometer (model 300001; SPER Scientific, Scottsdale, AZ), with a scale from 0 to $32 \%$ Brix. Both the digital and optical Brix refractometers measure the refractive index on a Brix scale (\% Brix). For the digital Brix refractometer, approximately 250 $\mu \mathrm{L}$ of colostrum was used, and then the Brix score was determined by transmitting light through the sample in the prism and recording the reading on a digital scale. For the optical Brix refractometer, approximately $50 \mu \mathrm{L}$ of colostrum was placed on the prism and the sample cover was lowered. The refractometer was then held up to a light source, and the Brix score was read through the viewfinder at the interface between light and dark areas. The refractometers were cleaned and calibrated with distilled water at room temperature before each analysis. The Brix scores were determined first by the optical refractometer, to avoid any bias in the results by the technician. Colostrum samples with a Brix score greater than the upper limit of the optical refractometer (32\% Brix) were considered good-quality colostrum for diagnostic tests; however, they had to be excluded from the descriptive, correlation, and receiver operating characteristic (ROC) curve data analyses (n $=18$ ).

\section{Data Analysis}

Descriptive statistics for the results of RID, IR spectroscopy, and digital and optical Brix refractometers were calculated and normality was assessed by application of the Shapiro-Wilkinson test. The IgG concentrations for each colostrum sample $(\mathrm{n}=255)$, as predicted by the IR spectroscopy, were plotted against the IgG concentrations measured by the reference RID method. The digital and optical Brix scores $(\mathrm{n}=240)$ were plotted against the RID IgG concentration. The correlations between IR spectroscopy, both refractometers, and the colostral RID IgG concentration were determined using the Spearman correlation coefficients.

The sensitivity (Se), specificity (Sp), accuracy, false positive (FP), and false negative $(\mathbf{F N})$ test results were calculated to evaluate the performance of IR spectroscopy and digital and optical refractometers to differentiate between poor- and good-quality colostrum, using an RID IgG concentration of $50 \mathrm{~g} / \mathrm{L}$ as a cutoff value. Sensitivity was defined as the proportion of poor-quality samples $(<50 \mathrm{~g} / \mathrm{L})$ that were correctly identified as such, and Sp was defined as the proportion of good-quality samples $(\geq 50 \mathrm{~g} / \mathrm{L})$ that were correctly identified as such. Accuracy was defined as the proportion of colostrum samples that were correctly classified. For IR spectroscopy and digital and optical refractometers, 5 cutoff values were considered, and the computed Se, Sp, and accuracy for each of the possible cutoff values were tabulated. The best cutoff value was defined as the one that gave the optimal combination of Se, Sp, and accuracy.

The ROC curve was created to plot the true positive rate against the false positive rate for IR spectroscopy and both the digital and optical refractometers. The area under the curve in the ROC plot, with a $95 \%$ confidence interval, was calculated. The area under the ROC curve, a commonly used index of the overall ability of a test to discriminate a target condition, was 
used to compare the performance of IR spectroscopy and each of the refractometers. To examine the performance of the IR spectroscopy and refractometers in different populations, with varying poor-quality colostrum percentages, the positive predictive value (PPV), negative predictive value (NPV), and positive predictive value of a negative test $(\mathbf{P P V N}=1-\mathrm{NPV}$; Dohoo et al., 2009) were calculated at previously reported prevalences of poor-quality colostrum. The PPV was the proportion of test-positive samples that truly had $\operatorname{IgG}<50 \mathrm{~g} / \mathrm{L}$, and the NPV was the proportion of test-negative samples that truly had $\operatorname{IgG} \geq 50 \mathrm{~g} / \mathrm{L}$. The level of agreement between results of IR spectroscopy and digital and optical refractometers compared with the reference RID assay was assessed using kappa analysis and McNemar's test (Lachenbruch and Lynch, 1998) for paired data to check for bias. These calculations were performed with Stata version 13.0 statistical software (StataCorp, 2013).

\section{RESULTS}

\section{Descriptive Statistics}

The colostral IgG concentration measured by the reference RID assay ranged from 8.4 to $232.4 \mathrm{~g} / \mathrm{L}$. The average $\operatorname{IgG}$ concentration was $64.7 \pm 44.6 \mathrm{~g} / \mathrm{L}$ and the median was $50.6 \mathrm{~g} / \mathrm{L}$. The RID assay indicated that 48\% (123 of 258) of colostrum samples had IgG concentrations below the cutoff value of $50 \mathrm{~g} / \mathrm{L}$ (poor quality). The frequency distribution of the colostral IgG concentrations measured by the reference RID and IR spectroscopy were skewed to the right (ShapiroWilkinson $P<0.05$; Figure 1A). However, distribution of the Brix scores measured by the digital and optical refractometers were approximately normally distributed (Shapiro-Wilkinson $P>0.05$; Figure 1B).

\section{Correlation Coefficients}

The correlations between the reference RID assay and IR spectroscopy and digital and optical Brix refractometers were examined using correlation plots (Figure 2). The correlation between RID- and IR-measured IgG was $0.88(P<0.001 ; \mathrm{n}=255$; Figure $2 \mathrm{~A})$. The correlations between RID values and Brix scores from the digital and optical refractometer were 0.72 and 0.71 , respectively $(P<0.001 ; \mathrm{n}=240 ;$ Figure $2 \mathrm{~B})$. The correlation between Brix scores from the digital and optical refractometers was 0.99 .

\section{Diagnostic Test Characteristics}

The test characteristics of the IR spectroscopy and digital and optical Brix refractometers were determined for the assessment of poor-quality colostrum (colostral $\operatorname{IgG}<50 \mathrm{~g} / \mathrm{L}$ ). The Se, Sp, accuracy, FP, and FN for the IR spectroscopy and digital and optical refractometers at previously recommended cutoff values are shown in Table 1 . The best combination of Se, Sp, and accuracy was achieved at a cut-point of $35 \mathrm{~g} / \mathrm{L}$ for IR spectroscopy and 23\% Brix for both refractometers. A ROC was created to plot the true positive rate against the false positive rate for the IR spectroscopy and the digital and optical refractometers (Figure 3). The AUC of the IR spectroscopy and the digital and optical refractometers were 0.96 (95\% CI: 0.94-0.98), 0.79 (95\% CI: $0.72-0.84$ ), and 0.78 (95\% CI: $0.71-0.84)$ respectively. Table 2 illustrates the PPV, NPV, and PPVN of the IR spectroscopy and digital and optical Brix refractometers at previously reported prevalences of poor-quality colostrum.

\section{Agreement with RID Assay}

The overall percentages of agreement between the reference RID assay, IR spectroscopy, digital refractom-

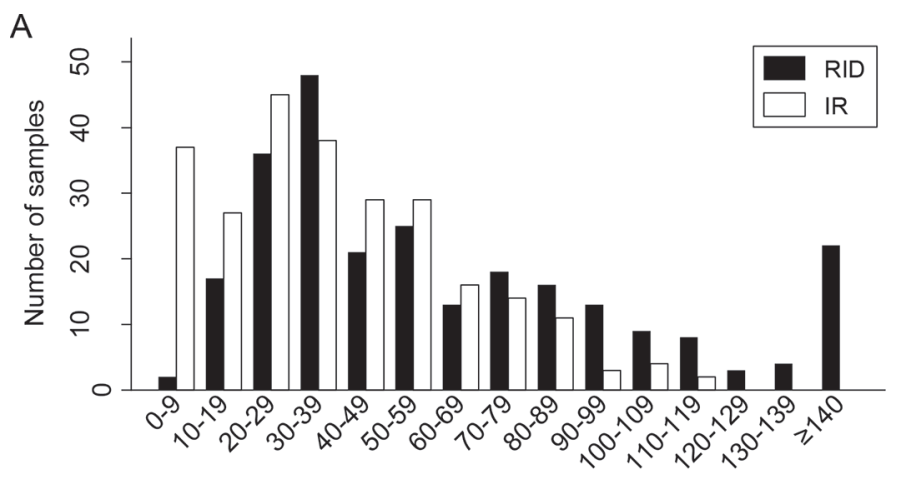

IgG concentration from RID and IR assays ( $g / L$ )

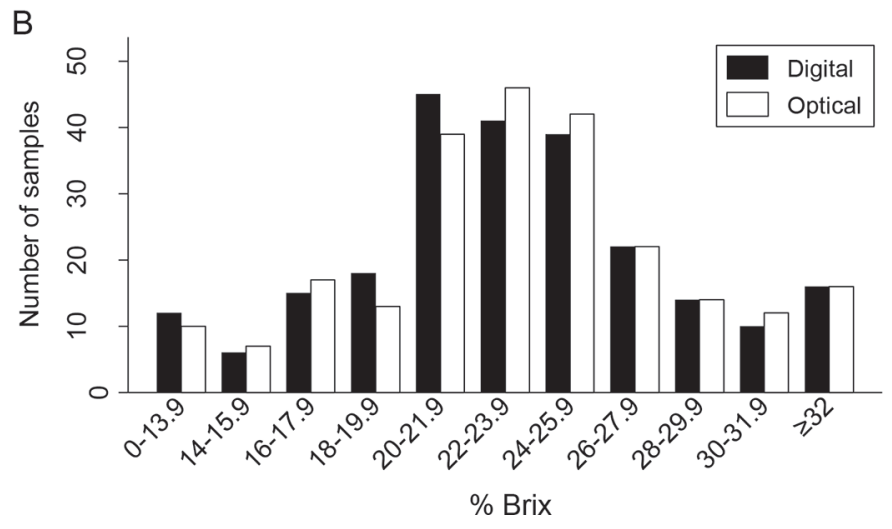

Figure 1. (A) Distribution of colostral IgG concentrations measured by radial immunodiffusion (RID) assay and predicted by infrared (IR) spectroscopy for 255 colostrum samples. (B) Distribution of Brix scores (\% Brix) measured by the digital and optical refractometers for 240 colostrum samples. 
eter, and optical refractometer for assessment of colostrum quality are presented in Table 3. The McNemar's test for comparison of Se and Sp showed no significant difference ( $P=0.32$ and $P=0.65$, respectively) between the proportion of colostrum samples correctly classified as poor and good quality by the 2 refractometers. However, we noted a significant difference $(P=0.0012)$ in the proportion of colostrum samples classified as poor quality by the IR spectroscopy and 2 refractometers.

\section{DISCUSSION}

Colostral IgG concentration has traditionally been considered the hallmark for evaluating colostrum quality (Godden et al., 2009). Several diagnostic tests are available for measuring colostral IgG concentrations, including RID, IR spectroscopy, and refractometers (Bielmann et al., 2010; Bartier et al., 2015; Løkke et al., 2016). The aim of our study was to determine and compare the diagnostic test characteristics of IR spectroscopy and digital and optical Brix refractometers as rapid methods for assessing colostrum quality.

In the current study, the average colostral IgG concentration measured by RID (64.7 g/L) was similar to data recently reported in dairy herds in Canada by Bartier et al. $(2015 ; 63.7 \mathrm{~g} / \mathrm{L})$, the United States by Morrill et al. (2012; 68.8), and Denmark by Løkke et al. $(2016 ; 59.7 \mathrm{~g} / \mathrm{L})$, but was lower than the IgG concentrations reported by Bielmann et al. (2010; $94.4 \mathrm{~g} / \mathrm{L})$ and Quigley et al. (2013; $73.4 \mathrm{~g} / \mathrm{L})$. In the present study, $48 \%$ of colostrum samples had RID IgG concentrations $<50 \mathrm{~g} / \mathrm{L}$, which was higher than that reported by Bartens et al. (2016; 34.7\%), Chigerwe et al. (2008; 32\%), Bartier et al. (2015; 29.1\%), and Bielmann et al. (2010; 7.7\%). Several factors may explain the differences in the distribution of $\operatorname{IgG}$ concentration values between the present study and previous studies. Sample size may have played a role, as in this study only 258 cows from 30 herds were enrolled and colostrum samples were not randomly collected during the study period. Therefore, the samples did not represent a valid prevalence estimate for poor-quality colostrum in these herds. The previous studies sampled 569 cows from 13 farms (Bartier et al., 2015), 827 cows from 67 farms (Morrill et al., 2012), and 288 cows from 3 herds (Bielmann et al., 2010). The larger the number of farms included in a study, the greater the variability in environmental, management, and nutritional practices that are known to affect colostrum quality (Godden, 2008). The time of colostrum collection after calving may also have affected the colostral IgG levels (Hostetler et al., 2003; Moore et al., 2005; Chigerwe et al., 2008). In the current study, the colostrum collection was done by cooperating farmers and time of collection relative to calving was between 1 to $15 \mathrm{~h}$. Colostrum samples collected within 1 to $2 \mathrm{~h}$ of calving are significantly higher in IgG concentration than colostrum collected more than $2 \mathrm{~h}$ after calving (data not shown). Furthermore, whereas farmers were instructed to collect first feeding samples, it is likely that some second or later feeding colostrum samples were collected and submitted, especially for the samples collected $>2 \mathrm{~h}$ after calving. Having almost half the samples being of poor-quality colostrum, although probably not a reflection of the true prevalence on these farms, is beneficial for our study, with the focus on assessment of the Se and Sp of these 3 assays.
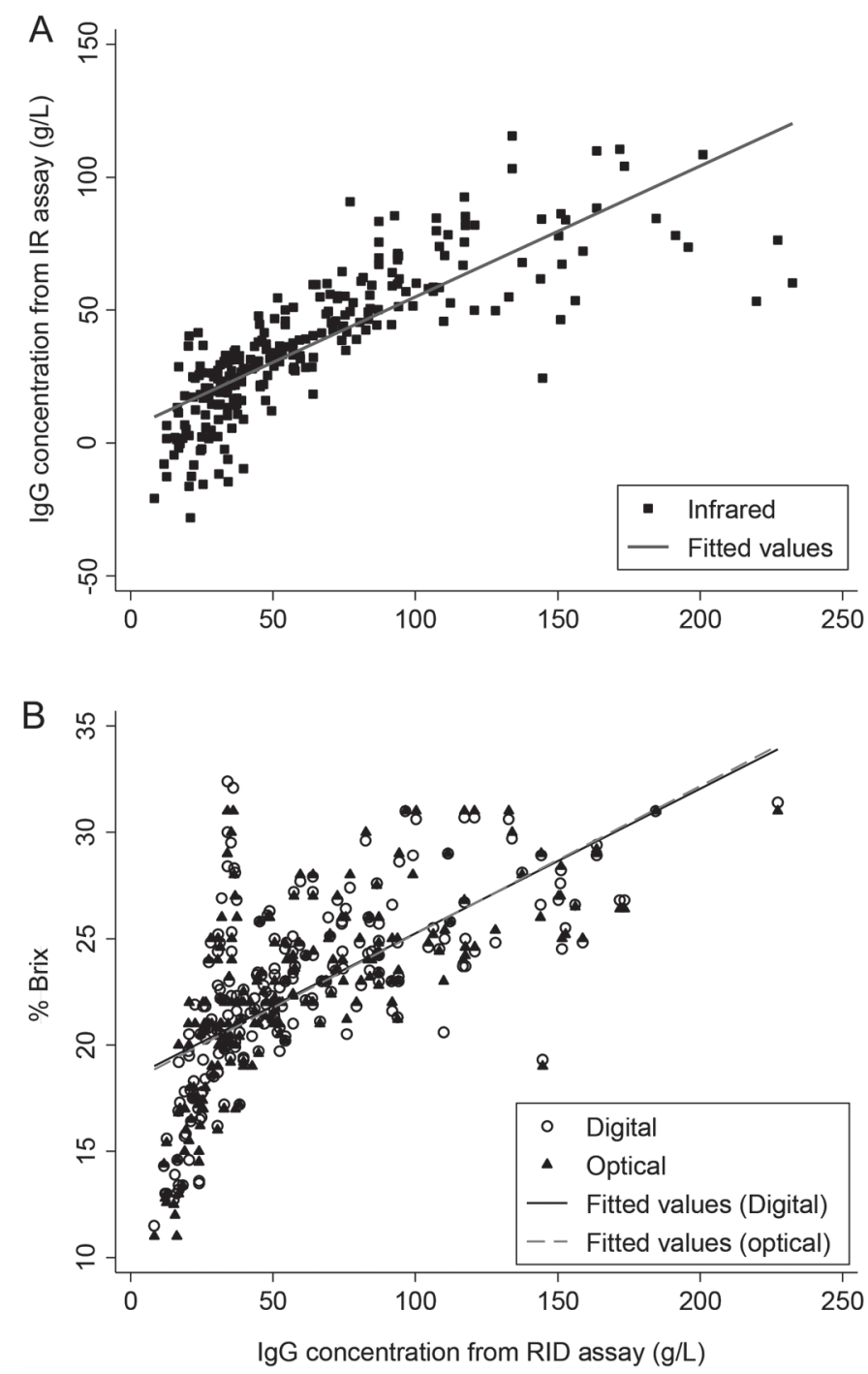

Figure 2. Scatter plots of colostral IgG concentrations obtained by radial immunodiffusion (RID) assay and (A) IgG concentration predicted by infrared (IR) spectroscopy for 255 colostrum samples; (B) Brix scores (\% Brix) obtained by both the digital and optical refractometers for 240 colostrum samples. 


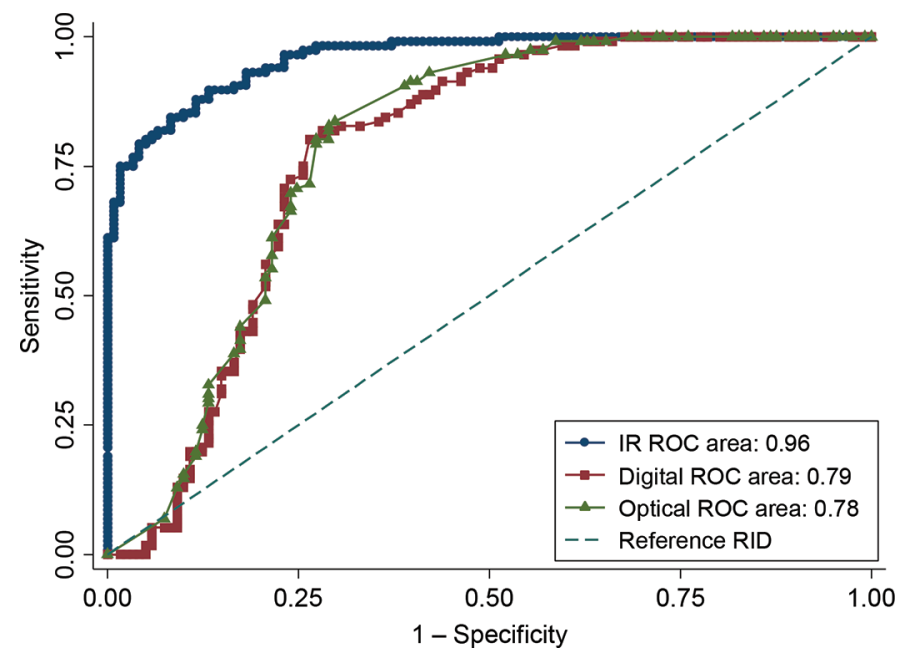

Figure 3. Receiver operating characteristic (ROC) curve analysis of the IgG concentration measured by the infrared (IR) spectroscopy and the Brix scores measured by the digital and optical Brix refractometers for 240 colostrum samples. RID = radical immunodiffusion. Color version available online.

The correlation coefficient of 0.88 between the IgG concentrations predicted by mid-IR spectroscopy and the RID assay (Figure 2A) was higher than the 0.85 reported by Løkke et al. (2016), who used mid-IR spectroscopy, and lower than the 0.97 reported by Rivero et al. (2012), who used near-IR spectroscopy to predict colostral IgG concentration. The wide range of reported correlation coefficients could be explained by the variations in the source of colostrum. In the current study, 255 samples were collected from 30 farms, whereas 126 samples from 21 farms and 157 samples from 2 farms were collected for Løkke et al. (2016) and Rivero et al. (2012), respectively. Furthermore, in the mid-IR study by Løkke et al. (2016) and near-IR study by Rivero et al. (2012), the colostrum samples collected were used to build the calibration model (PLS model) used to predict IgG concentration in these samples. However, the calibration model used for predicting IgG concentration in our study was previously built, using a different set of colostrum samples $(\mathrm{n}=251)$ than used in the current study (Elsohaby et al., 2016b); thus, the robustness and ability of the calibration model to predict IgG levels in future samples collected in the field was demonstrated. The IgG concentration predicted by the IR spectroscopic method showed a correlation with the reference RID assay higher than those reported for refractometry (Bielmann et al., 2010; Morrill et al., 2015; Løkke et al., 2016) and colostrometer (Bartier et al., 2015; Løkke et al., 2016; Bartens et al., 2016).

The correlation between IgG measured by RID and Brix scores determined by both the digital and optical refractometers (Figure 2B) was higher than the relationship reported by Chigerwe et al. (2008) and Bartier et al. (2015), similar to that reported by Bielmann et al. (2010) and Quigley et al. (2013), and slightly lower than the relationship reported by Morrill et al. (2015).

Table 1. Diagnostic test characteristics for the infrared (IR) spectroscopy and digital and optical Brix refractometers for assessing colostrum quality using previously recommended cut-points compared with reference classification based on radial immunodiffusion and a cut-point of $<50 \mathrm{~g} / \mathrm{L}$ of IgG

\begin{tabular}{|c|c|c|c|c|c|}
\hline \multirow[b]{2}{*}{ Cutoff level } & \multicolumn{5}{|c|}{ Test characteristic $^{1}(\%)$} \\
\hline & Se $(95 \%$ CI $)$ & Sp $(95 \%$ CI $)$ & Accuracy & $\mathrm{FP}$ & $\mathrm{FN}$ \\
\hline \multicolumn{6}{|c|}{ Infrared $(\mathrm{g} / \mathrm{L})$} \\
\hline 30 & $81(73-88)$ & $94(88-97)$ & 88 & 6 & 19 \\
\hline 35 & $90(83-94)$ & $86(78-91)$ & 87 & 14 & 10 \\
\hline 40 & $96(91-99)$ & $79(71-85)$ & 87 & 21 & 4 \\
\hline 45 & $99(97-100)$ & $71(62-79)$ & 85 & 29 & 1 \\
\hline 50 & $100(97-100)$ & $60(51-69)$ & 80 & 40 & 0 \\
\hline \multicolumn{6}{|c|}{ Digital (\% Brix) } \\
\hline 20 & $41(32-50)$ & $98(94-100)$ & 69 & 2 & 59 \\
\hline 21 & $54(44-63)$ & $93(87-97)$ & 73 & 7 & 46 \\
\hline 22 & $64(55-73)$ & $85(77-91)$ & 74 & 15 & 36 \\
\hline 23 & $74(65-82)$ & $80(72-87)$ & 77 & 20 & 26 \\
\hline 24 & $78(70-85)$ & $64(55-73)$ & 71 & 36 & 22 \\
\hline \multicolumn{6}{|c|}{ Optical (\% Brix) } \\
\hline 20 & $38(30-47)$ & $99(95-100)$ & 68 & 1 & 62 \\
\hline 21 & $49(40-58)$ & $97(92-99)$ & 72 & 3 & 51 \\
\hline 22 & $62(53-70)$ & $91(84-95)$ & 76 & 9 & 38 \\
\hline 23 & $73(64-81)$ & $80(71-86)$ & 76 & 20 & 27 \\
\hline 24 & $76(68-84)$ & $67(57-75)$ & 72 & 33 & 24 \\
\hline
\end{tabular}

${ }^{1} \mathrm{Se}=$ sensitivity; $\mathrm{Sp}=$ specificity; Accuracy = percentage of colostrum samples correctly classified as good $(\geq 50 \mathrm{~g} / \mathrm{L})$ or poor $(<50 \mathrm{~g} / \mathrm{L})$ quality; FP (false positive) = percentage of false positive samples; FN (false negative $)=$ percentage of false negative samples. 
Table 2. Positive and negative predictive values and positive predictive value of a negative test for infrared (IR) spectroscopy and digital and optical refractometers at previously reported prevalences of poor-quality colostrum $(<50 \mathrm{~g} / \mathrm{L} \mathrm{of} \operatorname{IgG})^{1}$

\begin{tabular}{|c|c|c|c|c|c|c|c|c|c|c|}
\hline \multirow[b]{2}{*}{$\begin{array}{l}\text { Prevalence } \\
(\%)\end{array}$} & \multirow[b]{2}{*}{ Study } & \multicolumn{3}{|c|}{ IR spectroscopy } & \multicolumn{3}{|c|}{ Digital refractometer } & \multicolumn{3}{|c|}{ Optical refractometer } \\
\hline & & $\begin{array}{c}\text { PPV } \\
(\%)\end{array}$ & $\begin{array}{l}\text { NPV } \\
(\%)\end{array}$ & $\begin{array}{c}\text { PPVN } \\
(\%)\end{array}$ & $\begin{array}{c}\mathrm{PPV} \\
(\%)\end{array}$ & $\begin{array}{l}\mathrm{NPV} \\
(\%)\end{array}$ & $\begin{array}{c}\text { PPVN } \\
(\%)\end{array}$ & $\begin{array}{c}\text { PPV } \\
(\%)\end{array}$ & $\begin{array}{l}\text { NPV } \\
(\%)\end{array}$ & $\begin{array}{c}\text { PPVN } \\
(\%)\end{array}$ \\
\hline 8 & Bielmann et al., 2010 & 35 & 99 & 1 & 25 & 97 & 3 & 24 & 97 & 3 \\
\hline 16 & Quigley et al., 2013 & 54 & 98 & 2 & 42 & 94 & 6 & 41 & 94 & 6 \\
\hline 30 & Bartier et al., 2015 & 73 & 95 & 5 & 62 & 88 & 12 & 61 & 87 & 13 \\
\hline 35 & Bartens et al., 2016 & 77 & 94 & 8 & 67 & 85 & 15 & 77 & 76 & 24 \\
\hline
\end{tabular}

${ }^{1} \mathrm{PPV}=$ positive predictive values; $\mathrm{NPV}=$ negative predictive values; PPVN $=$ positive predictive value of a negative test $(1-\mathrm{NPV})$.

Variations in the correlation coefficients in these studies could be due to the differences in the non-IgG contents in the colostrum. The Brix refractometer measures IgG concentrations indirectly, through measuring total dissolved solids in colostrum, which are affected by dry period length (Rastani et al., 2005), vaccination status of the dam (Hodgins and Shewen, 1996), and season of calving (Morin et al., 2001).

Appropriate cut-points need to be determined to ensure that only good-quality colostrum is fed to newborn calves and only poor-quality colostrum discarded. The diagnostic test characteristics of the IR spectroscopy and digital and optical refractometers were established at different cutoff levels for each method (Table 1). The sensitivity of a colostrum quality test is the probability for detection of colostrum samples of poor quality $(\mathrm{IgG}<50 \mathrm{~g} / \mathrm{L})$. Although maximizing the Se will increase the possibility of detecting and discarding poor-quality colostrum, it increases the risk of discarding good-quality colostrum (FP increases). A previous study suggested that the appropriate cut-point for IR spectroscopy to differentiate between poor- and goodquality colostrum lies between 45 and $55 \mathrm{~g} / \mathrm{L}$ (Løkke et al., 2016). In the current study, IR spectroscopy at a cutoff value $30 \mathrm{~g} / \mathrm{L}$ achieved the highest accuracy, but $19 \%$ of poor-quality colostrum was classified as good (Table 1). Increasing the cutoff value would increase the Se and risk of discarding good-quality colostrum (FP). Therefore, the recommended cut-point for IR spectroscopy was $35 \mathrm{~g} / \mathrm{L}$, where the optimal combinations of Se, Sp, and accuracy were achieved (Table 1). The recommended cut-point for IR spectroscopy (35 $\mathrm{g} / \mathrm{L})$ was lower than that reported for the reference RID assay $(50 \mathrm{~g} / \mathrm{L})$. This may be because of the large number of poor-quality colostrum samples (61\%) used to build the calibration model (Elsohaby et al., 2016b). As a result, the calibration model was weighted toward colostrum samples with low IgG levels. For the digital and optical Brix refractometers, the optimal cutoff value was at $23 \%$ Brix. The value for the digital Brix refractometer was similar to the finding of Bartens et al. (2016) and Bartier et al. (2015), but higher than the 21 and $22 \%$ Brix reported by others (Bielmann et al., 2010; Quigley et al., 2013; Løkke et al., 2016). For the optical Brix refractometer, the cutoff value was lower than the 27\% Brix reported by Bartens et al. (2016). Using a lower cutoff value (21 or $22 \%$ Brix) for the digital and optical refractometers would increase the risk of misclassifying poor colostrum as good colostrum (Table 1). The Se and Sp of IR spectroscopy we determined were higher than those reported by Løkke et al. (2016). Whereas, for refractometers, the values were close to those reported by Bartier et al. (2015) and Quigley et al. (2013) for the digital refractometer and lower than those reported by Bielmann et al. (2010) for both the digital and optical refractometers; this difference could be attributed to the use of refractometers from different manufacturers.

Results of the ROC analysis for the 3 methods (Figure 3 ) showed marked differences between the IR spectroscopy and the 2 refractometers for assessing colostrum quality. The IR spectroscopy showed greater Se, Sp, and accuracy than the 2 refractometers. Furthermore, the IR spectroscopy showed, relatively, higher PPV, NPV,

Table 3. Level of agreement between the infrared (IR) spectroscopy, digital and optical Brix refractometers, and radial immunodiffusion (RID) assay for evaluating colostrum quality

\begin{tabular}{llccc}
\hline Test & \multicolumn{1}{c}{ Cutoff } & Agreement & Kappa & $P$-value \\
\hline IR vs. RID & 35 (g/L) & 0.88 & 0.75 & 0.0001 \\
Digital vs. RID & 23 (\% Brix) & 0.77 & 0.54 & 0.0001 \\
Optical vs. RID & 23 (\% Brix) & 0.76 & 0.53 & 0.0001 \\
Digital vs. optical & 23 (\% Brix) & 0.98 & 0.95 & 0.0001 \\
\hline
\end{tabular}


and lower PPVN than the 2 refractometers over all the reported poor colostrum prevalences (Table 2). Similar results were reported by Løkke et al. (2016). When the proportion of poor-quality colostrum increased, NPV decreased. For example, at a low (8\%) and high (48\%) prevalence of poor-quality colostrum, the NPV of IR spectroscopy were 99 and 90\%, respectively; however, the NPV of the Brix refractometer were 97 and $75 \%$, respectively. Subsequently, the proportion of poorquality colostrum that would be saved when IR spectroscopy and Brix refractometers used would be very small (1 and 3\%, respectively) for low-prevalence herds and relatively large (10 and $25 \%$, respectively) for highprevalence herds. The PPV of the IR spectroscopy and Brix refractometers were relatively low. As a result, a substantial number of good-quality colostrum would be misclassified as poor-quality colostrum, and this misclassification would be more pronounced in herds with a low proportion of poor-quality colostrum.

The IR spectroscopy showed a high level of agreement (kappa $=0.75$ ) with the reference RID assay. However, the digital and optical refractometers only showed moderate agreement with the RID assay (Table $3)$. The digital refractometer showed also a high level of agreement (kappa $=0.95)$ with the optical refractometer and the McNemar's test showed no significant difference in either their Se or Sp, indicating that the digital and optical refractometers performed similarly for assessing colostrum quality. Similar results were reported for the use of digital and optical refractometers in the assessment of colostrum quality (Bielmann et al., 2010) and passive immunity transfer in dairy calves (Elsohaby et al., 2015; Thornhill et al., 2015).

\section{CONCLUSIONS}

Both IR spectroscopy and digital and optical Brix refractometers show potential for being effective management tools to be included in a colostrum-monitoring program. The IR spectroscopy can be used for rapid quantification of colostral IgG levels and, thus, for assessment of colostrum quality at a cut-point of $35 \mathrm{~g} / \mathrm{L}$. The IR spectroscopy provided the most accurate assessment of colostrum quality compared with the digital or optical Brix refractometers; however, it is an expensive laboratory-based instrument. The Brix refractometers were less accurate, but can be used to assess colostrum quality on-farm, for which we recommend a cutoff level of $23 \%$ Brix. A compact, portable IR spectroscopy is available, suggesting the real possibility of using the IR technique under field conditions. A study to assess the portable IR spectroscopy for determining colostrum quality on-farm is warranted.

\section{ACKNOWLEDGMENTS}

The authors thank summer program students, participating dairy farmers and veterinarians, as well as Theresa Andrews, Cynthia Mitchell, and Natasha Robinson (Maritime Quality Milk Laboratory, Charlottetown, PEI, Canada) for their technical assistance and data collection. The authors also thank William Chalmers (Department of Health Management, Atlantic Veterinary College) for technical assistance in preparation of the manuscript. This research was funded by Zoetis (Kirkland, QC, Canada) and the Atlantic Canada Opportunities Agency (Charlottetown, PEI, Canada).

\section{REFERENCES}

Bartens, M. C., M. Drillich, K. Rychli, M. Iwersen, T. Arnholdt, L. Meyer, and D. Klein-Jöbstl. 2016. Assessment of different methods to estimate bovine colostrum quality on farm. N. Z. Vet. J. 64:263-267.

Bartier, A. L., M. C. Windeyer, and L. Doepel. 2015. Evaluation of on-farm tools for colostrum quality measurement. J. Dairy Sci. 98:1878-1884.

Bielmann, V., J. Gillan, N. R. Perkins, A. L. Skidmore, S. Godden, and K. E. Leslie. 2010. An evaluation of Brix refractometry instruments for measurement of colostrum quality in dairy cattle. J. Dairy Sci. 93:3713-3721.

Burns, J., S. Hou, C. Riley, R. Shaw, N. Jewett, and J. McClure. 2014. Use of Fourier-transform infrared spectroscopy to quantify immunoglobulin $\mathrm{G}$ concentrations in alpaca serum. J. Vet. Intern. Med. 28:639-645.

Calloway, C. D., J. W. Tyler, R. K. Tessman, D. Hostetler, and J. Holle. 2002. Comparison of refractometers and test endpoints in the measurement of serum protein concentration to assess passive transfer status in calves. J. Am. Vet. Med. Assoc. 221:1605-1608.

CCAC. 2009. The Care and Use of Farm Animals in Research, Teaching and Testing. Canadian Council on Animal Care (CCAC), Ottawa, ON.

Chigerwe, M., J. W. Tyler, J. R. Middleton, J. N. Spain, J. S. Dill, and B. J. Steevens. 2008. Comparison of four methods to assess colostral IgG concentration in dairy cows. J. Am. Vet. Med. Assoc. 233:761-766.

Dohoo, I., W. Martin, and H. Stryhn. 2009. Screening and diagnostic tests. Pages 85-120 in Veterinary Epidemiologic Research, 2nd ed. University of Prince Edward Island, Charlottetown, PEI, Canada.

Donovan, G. A., I. R. Dohoo, D. M. Montgomery, and F. L. Bennett. 1998. Associations between passive immunity and morbidity and mortality in dairy heifers in Florida, USA. Prev. Vet. Med. 34:31-46.

Elsohaby, I., J. T. McClure, S. Hou, C. B. Riley, R. A. Shaw, and G. P. Keefe. 2016b. A novel method for the quantification of bovine colostral immunoglobulin G using infrared spectroscopy. Int. Dairy J. 52:35-41.

Elsohaby, I., J. T. McClure, and G. P. Keefe. 2015. Evaluation of digital and optical refractometers for assessing failure of transfer of passive immunity in dairy calves. J. Vet. Intern. Med. 29:721-726.

Elsohaby, I., J. T. McClure, C. B. Riley, R. A. Shaw, and G. P. Keefe. 2016a. Quantification of bovine immunoglobulin G using transmission and attenuated total reflectance infrared spectroscopy. J. Vet. Diagn. Invest. 28:30-37.

Elsohaby, I., C. B. Riley, S. Hou, J. T. McClure, R. A. Shaw, and G. P. Keefe. 2014. Measurement of serum immunoglobulin G in dairy cattle using Fourier-transform infrared spectroscopy: A reagent free approach. Vet. J. 202:510-515.

Fleenor, W. A., and G. Stott. 1980. Hydrometer test for estimation of immunoglobulin concentration in bovine colostrum. J. Dairy Sci. 63:973-977. 
Godden, S. 2008. Colostrum management for dairy calves. Vet. Clin. North Am. Food Anim. Pract. 24:19-39.

Godden, S. M., D. Haines, and D. Hagman. 2009. Improving passive transfer of immunoglobulins in calves. I: Dose effect of feeding a commercial colostrum replacer. J. Dairy Sci. 92:1750-1757.

Hodgins, D. C., and P. E. Shewen. 1996. Preparturient vaccination to enhance passive immunity to the capsular polysaccharide of Pasteurella haemolytica A1. Vet. Immunol. Immunopathol. 50:67-77.

Hostetler, D., V. Douglas, J. Tyler, J. Holle, and B. Steevens. 2003. Immunoglobulin $\mathrm{G}$ concentrations in temporal fractions of first milking colostrum in dairy cows. Int. J. Appl. Res. Vet. Med. 1:168-171.

Lachenbruch, P. A., and C. J. Lynch. 1998. Assessing screening tests: Extensions of McNemar's test. Stat. Med. 17:2207-2217.

Løkke, M. M., R. Engelbrecht, and L. Wiking. 2016. Covariance structures of fat and protein influence the estimation of $\operatorname{IgG}$ in bovine colostrum. J. Dairy Res. 83:58-66.

McBeath, D. G., W. J. Penhale, and E. F. Logan. 1971. An examination of the influence of husbandry on the plasma immunoglobulin level of the newborn calf, using a rapid refractometer test for assessing immunoglobulin content. Vet. Rec. 88:266-270.

Mechor, G. D., Y. Gröhn, L. McDowell, and R. Van Saun. 1992. Specific gravity of bovine colostrum immunoglobulins as affected by temperature and colostrum components. J. Dairy Sci. 75:31313135 .

Moore, M., J. W. Tyler, M. Chigerwe, M. E. Dawes, and J. R. Middleton. 2005. Effect of delayed colostrum collection on colostral IgG concentration in dairy cows. J. Am. Vet. Med. Assoc. 226:13751377.

Morin, D. E., P. Constable, F. Maunsell, and G. McCoy. 2001. Factors associated with colostral specific gravity in dairy cows. J. Dairy Sci. 84:937-943.

Morrill, K. M., E. Conrad, A. Lago, J. Campbell, J. Quigley, and H. Tyler. 2012. Nationwide evaluation of quality and composition of colostrum on dairy farms in the United States. J. Dairy Sci. 95:3997-4005.

Morrill, K. M., K. Robertson, M. Spring, A. Robinson, and H. Tyler. 2015. Validating a refractometer to evaluate immunoglobulin $\mathrm{G}$ concentration in jersey colostrum and the effect of multiple freeze-thaw cycles on evaluating colostrum quality. J. Dairy Sci. 98:595-601.

Oyeniyi, O. O., and A. Hunter. 1978. Colostral constituents including immunoglobulins in the first three milkings postpartum. J. Dairy Sci. 61:44-48.

Pritchett, L. C., C. C. Gay, T. E. Besser, and D. D. Hancock. 1991 Management and production factors influencing immunoglobulin G1 concentration in colostrum from Holstein Cows1. J. Dairy Sci. 74:2336-2341.

Quigley, J. D., A. Lago, C. Chapman, P. Erickson, and J. Polo. 2013. Evaluation of the Brix refractometer to estimate immunoglobulin G concentration in bovine colostrum. J. Dairy Sci. 96:1148-1155.

Rastani, R. R., R. Grummer, S. Bertics, A. Gümen, M. Wiltbank, D. Mashek, and M. Schwab. 2005. Reducing dry period length to simplify feeding transition cows: Milk production, energy balance, and metabolic profiles. J. Dairy Sci. 88:1004-1014.
Rauprich, A. B., H. Hammon, and J. Blum. 2000. Influence of feeding different amounts of first colostrum on metabolic, endocrine, and health status and on growth performance in neonatal calves. J. Anim. Sci. 78:896-908.

Riley, C. B., J. T. McClure, S. Low-Ying, and R. A. Shaw. 2007. Use of Fourier-transform infrared spectroscopy for the diagnosis of failure of transfer of passive immunity and measurement of immunoglobulin concentrations in horses. J. Vet. Intern. Med. 21:828-834.

Rivero, M. J., X. Valderrama, D. Haines, and D. Alomar. 2012. Prediction of immunoglobulin $\mathrm{G}$ content in bovine colostrum by nearinfrared spectroscopy. J. Dairy Sci. 95:1410-1418.

Robison, J. D., G. Stott, and S. DeNise. 1988. Effects of passive immunity on growth and survival in the dairy heifer ${ }^{1,2}$. J. Dairy Sci. $71: 1283-1287$.

Rutten, M. J., H. Bovenhuis, J. Heck, and J. van Arendonk. 2011a. Predicting bovine milk protein composition based on Fourier transform infrared spectra. J. Dairy Sci. 94:5683-5690.

Rutten, M. J., H. Bovenhuis, J. Heck, and J. van Arendonk. 2011b. Prediction of $\beta$-lactoglobulin genotypes based on milk Fourier transform infrared spectra. J. Dairy Sci. 94:4183-4188.

Santos, P. M., R. P. Edenir, and E. R. Luis. 2013. Application of handheld and portable infrared spectrometers in bovine milk analysis. J. Agric. Food Chem. 61:1205-1211.

Shaw, R. A., S. Kotowich, M. Leroux, and H. H. Mantsch. 1998. Multianalyte serum analysis using mid-infrared spectroscopy. Ann. Clin. Biochem. 35:624-632.

Shaw, R. A., and H. H. Mantsch. 1999. Vibrational biospectroscopy: From plants to animals to humans. A historical perspective. J. Mol. Struct. 480-481:1-13.

Shaw, R. A., and H. H. Mantsch. 2000. Infrared spectroscopy in clinical and diagnostic analysis. Pages 83-102 in Encyclopedia of Analytical Chemistry: Applications Theory and Instrumentation. R. A. Meyers, ed. Wiley Online Library, Chichester, UK.

StataCorp. 2013. Stata Statistical Software. StataCorp LP, College Station, TX

Thornhill, J. B., G. Krebs, and C. Petzel. 2015. Evaluation of the Brix refractometer as an on-farm tool for the detection of passive transfer of immunity in dairy calves. Aust. Vet. J. 93:26-30.

USDA. 2016. Dairy 2014, Part I: Dairy cattle management practices in the United States, 2014. \#N 692.0216. USDA-Animal and Plant Health Inspection Service-Veterinary Service, Center for Epidemiology and Animal Health, Fort Collins, CO.

Vasseur, E., F. Borderas, R. I. Cue, D. Lefebvre, D. Pellerin, J. Rushen, K. M. Wade, and A. M. de Passille. 2010. A survey of dairy calf management practices in Canada that affect animal welfare. J. Dairy Sci. 93:1307-1315.

Virtala, A. M., Y. Gröhn, G. Mechor, and H. Erb. 1999. The effect of maternally derived immunoglobulin $\mathrm{G}$ on the risk of respiratory disease in heifers during the first 3 months of life. Prev. Vet. Med. $39: 25-37$.

Ward, K. J., D. M. Haaland, M. R. Robinson, and R. P. Eaton. 1989. Quantitative infrared spectroscopy of glucose in blood using partial least-squares analyses. Pages 607-608 in International Conference on Fourier and Computerized Infrared Spectroscopy. International Society for Optics and Photonics, Fairfax, VA. 